\title{
RESEARCH
}

Open Access

\section{Main differences between two highly effective lipid-lowering therapies in subclasses of lipoproteins in patients with acute myocardial infarction}

Leticia C. S. Pinto ${ }^{1}$, Ana P. Q. Mello', Maria C. O. Izar ${ }^{1}$, Nagila R. T. Damasceno², Antonio M. F. Neto', Carolina N. França", Adriano Caixeta', Henrique T. Bianco', Rui M. S. Póvoa', Flavio T. Moreira',

Amanda S. F. Bacchin ${ }^{1}$ and Francisco A. Fonseca ${ }^{1 *}$ (D)

\begin{abstract}
Background: Large observational studies have shown that small, dense LDL subfractions are related to atherosclerotic cardiovascular disease. This study assessed the effects of two highly effective lipid-lowering therapies in the atherogenic subclasses of lipoproteins in subjects with ST-segment elevation myocardial infarction (STEMI).

Methods: Patients of both sexes admitted with their first myocardial infarction and submitted to pharmacoinvasive strategy ( $N=101)$ were included and randomized using a central computerized system to receive a daily dose of simvastatin $40 \mathrm{mg}$ plus ezetimibe $10 \mathrm{mg}$ or rosuvastatin $20 \mathrm{mg}$ for 30 days. Intermediate-density lipoprotein (IDL) and low-density lipoprotein (LDL) subfractions were analysed by polyacrylamide gel electrophoresis (Lipoprint System) on the first (D1) and 30th days (D30) of lipid-lowering therapy. Changes in LDL and IDL subfractions between D1 and D30 were compared between the lipid-lowering therapies (Mann-Whitney U test).
\end{abstract}

Results: The classic lipid profile was similar in both therapy arms at D1 and D30. At D30, the achievement of lipid goals was comparable between lipid-lowering therapies. Cholesterol content in atherogenic subclasses of LDL $(p=$ $0.043)$ and IDL $(p=0.047)$ decreased more efficiently with simvastatin plus ezetimibe than with rosuvastatin.

Conclusions: Lipid-lowering therapy with simvastatin plus ezetimibe was associated with a better pattern of lipoprotein subfractions than rosuvastatin monotherapy. This finding was noted despite similar effects in the classic lipid profile and may contribute to residual cardiovascular risk.

Trial registration: ClinicalTrials.gov, NCT02428374, registered on 28/09/2014.

\footnotetext{
*Correspondence: fahfonseca@terra.com.br; fah.fonseca@unifesp.br

1 Escola Paulista de Medicina, Setor de Lípides, Aterosclerose e Biologia

Vascular, Universidade Federal de São Paulo, UNIFESP, Rua Loefgren 1350,

São Paulo, SP 04040-001, Brazil

Full list of author information is available at the end of the article
}

(c) The Author(s). 2021 Open Access This article is licensed under a Creative Commons Attribution 4.0 International License, which permits use, sharing, adaptation, distribution and reproduction in any medium or format, as long as you give appropriate credit to the original author(s) and the source, provide a link to the Creative Commons licence, and indicate if changes were made. The images or other third party material in this article are included in the article's Creative Commons licence, unless indicated otherwise in a credit line to the material. If material is not included in the article's Creative Commons licence and your intended use is not permitted by statutory regulation or exceeds the permitted use, you will need to obtain permission directly from the copyright holder. To view a copy of this licence, visit http://creativecommons.org/licenses/by/4.0/ The Creative Commons Public Domain Dedication waiver (http://creativecommons.org/publicdomain/zero/1.0/) applies to the data made available in this article, unless otherwise stated in a credit line to the data. 


\section{Introduction}

Highly effective statins alone or combined with ezetimibe have been recommended for high-risk patients, according to recent guidelines $[1,2]$. The achievement of target LDL-C levels seems important for plaque stability and a decrease in recurrent events after acute coronary syndrome [3-5]. However, the pattern of lipoprotein subfractions after lipid-lowering therapies also seems important. Small LDL particles are common in patients with hypertriglyceridemia. After the metabolism of triglyceride-enriched particles by lipoprotein lipase, followed by exchanges of triglycerides and cholesterol with other lipoproteins, mediated by the cholesterol ester transfer protein, further delipidation by hepatic lipase occurs, and small and dense LDL particles are formed [6]. For the same amount of cholesterol, a higher number of LDL particles are present among patients with small LDL subfractions. Due to the lower affinity of these particles for LDL receptors in the liver, prolonged circulation time favours oxidation and uptake by endothelial cells, contributing to plaque formation [6]. Recently, in a cohort of subjects without prior cardiovascular disease conducted in Japan, small, dense LDL was associated with a higher risk of coronary heart disease [7]. Accordingly, a meta-analysis involving 21 studies and 30,628 individuals confirmed the positive relationship between small, dense LDL and ischaemic heart disease [8]. Furthermore, in China, a country with one of the highest mortality rates from stroke, small and dense subclasses of LDL particles were more prevalent in subjects with acute ischaemic stroke [9]. The pattern of LDL particles can be examined by various methods, such as nuclear magnetic resonance, gradient gel electrophoresis, and ultracentrifugation, and differences between these methods have been reported [10]. Recently, a new equation using variables of the standard lipid panel was proposed and validated in a large cohort [11].

The greater effectiveness of combining ezetimibe to achieve LDL-C targets in relation to doubling statin doses has been established [12], but their effects on lipoprotein subfractions have been less reported, with the majority of studies finding a decrease in cholesterol content without a shift in the more or less atherogenic subfractions [13-18]. Interestingly, rosuvastatin therapy was associated with faster catabolism of large buoyant LDL particles [19].

Finally, residual inflammatory risk may be reduced by lipid-lowering therapy [20]. However, additional effects on high-sensitivity C-reactive protein (hsCRP) levels by ezetimibe therapy in subjects under statin therapy remain controversial [21, 22].

This work assessed the effects of two highly effective lipid-lowering therapies on the pattern of atherogenic subclasses of lipoproteins in patients with ST-segment elevation acute myocardial infarction (STEMI). Highly effective lipid-lowering therapies were considered those prescribed with the aim of achieving a $50 \%$ or greater reduction in LDL-C $[1,2]$.

\section{Methods \\ Study population}

For this study, 101 consecutive patients of both sexes with their first myocardial infarction were included as part of the B And T Types of Lymphocyte Evaluation in Acute Myocardial Infarction (BATTLE-AMI study, NCT02428374) [23]. All patients underwent pharmacological thrombolysis in the first $6 \mathrm{~h}$ followed by coronary angiogram and percutaneous coronary intervention (PCI) when needed in the first $24 \mathrm{~h}$ of STEMI (pharmacoinvasive strategy). Patients with primary PCI were not included in this trial. The key exclusion criteria were clinical instability, use of lipid-lowering or immunosuppressant therapies, autoimmune disease, known malignancy, pregnancy or signs of active infections. After hospital admission, these patients were randomized to be treated with simvastatin $40 \mathrm{mg}$ plus ezetimibe $10 \mathrm{mg}$ qd (Vytorin ${ }^{\oplus}, \mathrm{MSD}$ ) or rosuvastatin $20 \mathrm{mg}$ qd (Crestor ${ }^{\oplus}$, AstraZeneca) using a central computerized system (battle-ami.huhsp.org.br).

\section{Laboratory assays}

Laboratory analyses and coronary angiograms and PCI were performed in Hospital São Paulo (a tertiary universitary hospital). The lipoprotein subfraction analysis was assessed in Faculdade de Saude Publica (Universidade de Sao Paulo - USP).

Blood samples $(20 \mathrm{~mL})$ were collected on the same day of hospitalization or on the morning of the following day in case of overnight hospitalization (D1) and after 30 days of STEMI (D30) and were promptly stored at $-80^{\circ} \mathrm{C}$ until lipoprotein analysis. IDL and LDL subfractions were classified and measured by the Lipoprint System (Quantimetrix Corporation, CA, USA) according to the manufacturer's instructions $[24,25]$. The $\mathrm{LDL}_{1,2}$ subfractions were classified as large, buoyant LDLs (lbLDL), and subfractions $\mathrm{LDL}_{3}, 4,5,6$, 7 were classified as smaller and denser particles. LDL subfractions were adjusted by serum total cholesterol and are expressed as $\mathrm{mg} / \mathrm{dL}$.

Routine laboratory assays were performed in the Central Laboratory of the university hospital. Highsensitivity $\mathrm{C}$-reactive protein (hsCRP) was measured by immunonephelometry.

Estimation of small dense LDL (sdLDL) subfractions was also examined by the Sampson equation [11].

\section{Statistical analysis}

Statistical analysis was performed using SPSS version 18 (Armonk, NY, USA). The normality of continuous variables was examined by the Kolmogorov-Smirnov test. 
Data with a normal distribution are expressed as the mean $\pm \mathrm{SD}$, and non-Gaussian variables are expressed as the median (interquartile range [IQR]). Comparisons between groups were made by Student's $t$ test or the Mann-Whitney U test, as appropriate. Correlations between methods for sdLDL subfractions were made by Spearman's rank test. A convenience sample was used due to the lack of previous studies comparing these treatments. Significance was set at a $P$ value $<0.05$.

\section{Results}

A total of 101 patients were included in the study (Fig. 1). The main clinical characteristics of the study population are shown in Table 1 and did not differ between groups. All patients had their first STEMI, and the proportion of culprit coronary artery and infarct size estimated by highsensitivity troponin $\mathrm{T}$ (hsTNT) were similar in both groups.

\section{Classic lipid profiles}

Table 2 shows the classic lipid profiles at D1 and D30. Lipids were comparable at D1, and the effects of lipidlowering therapies were similar at D30. The proportions of LDL-C and non-HDL-C targets achieved according to the European Society of Cardiology/European Atherosclerosis Society [1] were comparable between groups. LDL-C $<55 \mathrm{mg} / \mathrm{dL}$ was achieved by $57 \%$ of those patients in the simvastatin plus ezetimibe group and by $46 \%$ in the rosuvastatin group. For non-HDL-C $<85 \mathrm{mg} /$ $\mathrm{dL}, 47$ and $51 \%$ of patients achieved these goals in the simvastatin plus ezetimibe and rosuvastatin groups, respectively. The achievement of LDL-C $<70 \mathrm{mg} / \mathrm{dL}$, suggested by the American College of Cardiology/American Heart Association [2], was observed in $67 \%$ of patients in the simvastatin plus ezetimibe group and in $60 \%$ of subjects treated with rosuvastatin $(P=0.51$, Pearson chisquare test).

Subfractions of intermediate-density lipoproteins (IDL) Non-atherogenic (IDL-A) and atherogenic subfractions of intermediate-density lipoproteins (IDL-B and IDL-C) are shown in Table 3. At D1, similar levels of cholesterol content in nonatherogenic IDL-A were found in both groups, but the cholesterol titers from the atherogenic subfractions of intermediate-density lipoproteins (IDL$B$ plus IDL-C) were higher in the simvastatin plus ezetimibe group. To examine the effects of therapies, delta analysis was performed. After 30 days of lipid-

\section{0 patients were assessed for eligibility}

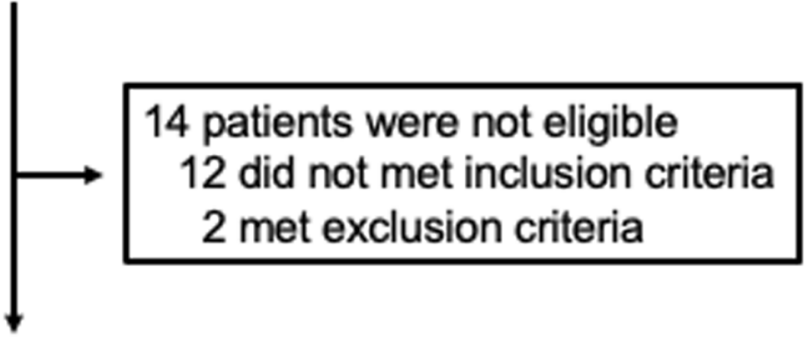

\section{6 patients were enrolled}

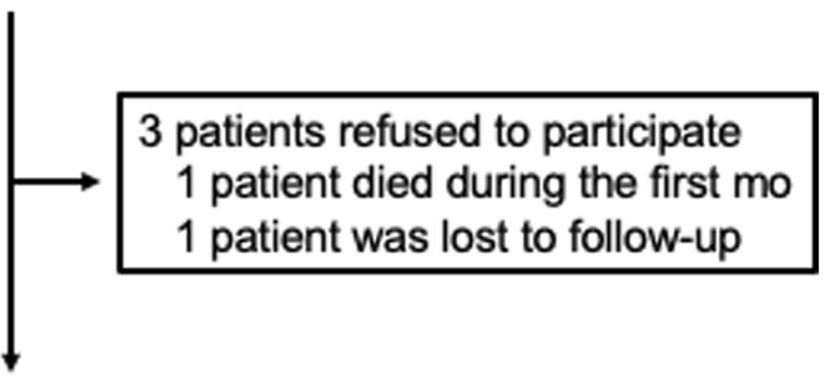

\section{1 patients completed trial}

Fig. 1 Flowchart. Only patients with a first myocardial infarction (STEMI) undergoing pharmacological thrombolysis during the first $6 \mathrm{~h}$ and coronary angiogram followed when necessary by percutaneous coronary intervention in the first $24 \mathrm{~h}$ were included. Patients receiving lipidlowering or immunosuppressive therapy and those with clinical instability and contraindications or known intolerances for the lipid-lowering drugs of the study were excluded. One patient died during the first month after myocardial infarction 
Table 1 Clinical and laboratory characteristics of the study population

\begin{tabular}{|c|c|c|c|}
\hline Parameter & $\begin{array}{l}\text { Simvastatin plus ezetimibe } \\
N=50\end{array}$ & $\begin{array}{l}\text { Rosuvastatin } \\
N=51\end{array}$ & $P$ value \\
\hline Age (years), & $59(52-65)$ & $58(55-64)$ & 0.78 \\
\hline Males, n (\%) & $39(76)$ & $36(72)$ & 0.77 \\
\hline Smokers, n (\%) & $34(67)$ & $37(74)$ & 0.56 \\
\hline Hypertensives, n (\%) & $36(71)$ & $36(72)$ & 0.77 \\
\hline Diabetes, n (\%) & $16(31)$ & $19(38)$ & 0.62 \\
\hline $\mathrm{BMl}, \mathrm{kg} / \mathrm{m} 2$ & $26.9(24.0-31.4)$ & $25.3(24.2-27.8)$ & 0.47 \\
\hline $\mathrm{HbA1c}(\%)$ & $6.0(5.5-6.7)$ & $6.0(5.6-6.7)$ & 0.60 \\
\hline Glucose, mg/dL & $129(99-169)$ & $121(105-167)$ & 0.78 \\
\hline hsTNT, ng/L & $5881(2273-12,231)$ & $5985(2409-10,020)$ & 0.55 \\
\hline Creatinine, mg/dL & $0.90(0.79-1.11)$ & $0.89(0.77-1.00)$ & 0.35 \\
\hline $\mathrm{GFR}, \mathrm{mL} / \mathrm{min} / \mathrm{m}^{2}$ & $86(70-93)$ & $86(73-98)$ & 0.79 \\
\hline $\mathrm{SBP}, \mathrm{mm} \mathrm{Hg}$ & $125(110-137)$ & $126(111-137)$ & 0.64 \\
\hline $\mathrm{DBP}, \mathrm{mm} \mathrm{Hg}$ & $80(67-83)$ & $78(71-89)$ & 0.48 \\
\hline \multicolumn{4}{|l|}{ Culprit coronary artery } \\
\hline Left anterior descending, n (\%) & $25(50)$ & $26(51)$ & 0.92 \\
\hline Right coronary artery, n (\%) & $18(36)$ & $19(37)$ & 0.90 \\
\hline Left circumflex artery, $\mathrm{n}(\%)$ & $7(14)$ & $6(12)$ & 0.74 \\
\hline
\end{tabular}

Continuous variables are medians (IQRs). LAD left anterior descending artery, RCA right coronary artery, LCX left circumflex, $h s T N T$ high-sensitivity troponin T.

Categorical variables were compared by Pearson's chi-square test, and continuous variables were compared by the Mann-Whitney $U$ test

lowering therapy, no significant differences in subfractions of IDL were found, but patients treated with simvastatin plus ezetimibe more efficiently decreased the cholesterol content in the atherogenic IDL subclasses (Delta, $P=0.047$ vs. rosuvastatin group, Mann-Whitney U test), whereas no differences were observed between groups for cholesterol from the nonatherogenic IDL-A (Fig. 2).

\section{Subfractions of low-density lipoprotein (LDL)}

Table 3 shows the cholesterol content of the LDL subfractions. At D1, both lipid-lowering groups had similar cholesterol concentrations of nonatherogenic LDL (LDL-1 and LDL-2) and atherogenic LDL subfractions (LDL-3 to LDL-7). At D30, no significant differences were observed for atherogenic and nonatherogenic LDL particles (Table 3), but simvastatin plus ezetimibe more

Table 2 Classic lipid profile at D1 and D30 by groups of lipid-lowering therapies

\begin{tabular}{|c|c|c|c|}
\hline Parameters & $\begin{array}{l}\text { Simvastatin plus ezetimibe } \\
N=50\end{array}$ & $\begin{array}{l}\text { Rosuvastatin monotherapy } \\
N=51\end{array}$ & $\begin{array}{l}P \\
\text { value }\end{array}$ \\
\hline \multicolumn{4}{|l|}{ At baseline (D1) } \\
\hline Cholesterol, mg/dL & $188(174-223)$ & $199(168-227)$ & 0.83 \\
\hline $\mathrm{LDL}-\mathrm{C}, \mathrm{mg} / \mathrm{dL}$ & $127(113-153)$ & $129(107-150)$ & 0.73 \\
\hline $\mathrm{HDL}-\mathrm{C}, \mathrm{mg} / \mathrm{dL}$ & $40(31-46)$ & $36(31-45)$ & 0.32 \\
\hline Triglycerides, mg/dL & $140(98-214)$ & 157 (98-232) & 0.42 \\
\hline Non-HDL-C, mg/dL & 154 (137-193) & 160 (139-193) & 0.92 \\
\hline \multicolumn{4}{|l|}{ After 30 days (D30) } \\
\hline Cholesterol, mg/dL & $121(98-141)$ & $119(105-141)$ & 0.53 \\
\hline $\mathrm{LDL}-\mathrm{C}, \mathrm{mg} / \mathrm{dL}$ & $58(43-82)$ & $61(50-82)$ & 0.39 \\
\hline $\mathrm{HDL}-\mathrm{C}, \mathrm{mg} / \mathrm{dL}$ & $37(31-44)$ & $37(32-40)$ & 0.93 \\
\hline Triglycerides, mg/dL & 133 (107-187) & $140(100-178)$ & 0.93 \\
\hline Non-HDL-C, mg/dL & $78(65-112)$ & $83(70-105)$ & 0.66 \\
\hline
\end{tabular}

Values are medians (IQRs). Blood samples were collected on the first (D1) and 30 (D30) days after myocardial infarction. Variables were compared by the MannWhitney $\mathrm{U}$ test 
Table 3 Cholesterol content in subfractions of intermediate- and low-density lipoproteins at baseline and after lipid-lowering therapy

\begin{tabular}{|c|c|c|c|}
\hline Lipoprotein subfractions & $\begin{array}{l}\text { Simvastatin plus ezetimibe } \\
N=50\end{array}$ & $\begin{array}{l}\text { Rosuvastatin monotherapy } \\
N=51\end{array}$ & $P$ value \\
\hline \multicolumn{4}{|l|}{ At baseline (D1) } \\
\hline IDL-A & $16.0(10.1-21.4)$ & $12.5(8.5-17.8)$ & 0.06 \\
\hline $\mathrm{IDL}-\mathrm{B}+\mathrm{C}$ & $40.1(31.9-49.4)$ & $35.2(24.6-43.9)$ & 0.02 \\
\hline $\mathrm{LDL}-1+2$ & $50.4(39.2-63.2)$ & $52.5(41.3-64.2)$ & 0.38 \\
\hline $\mathrm{LDL}-3+4+5+6+7$ & $3.6(0.0-9.9)$ & $2.8(0.0-5.7)$ & 0.09 \\
\hline \multicolumn{4}{|l|}{ After 30 days (D30) } \\
\hline IDL-A & $8.8(6.8-12.5)$ & $7.5(5.8-10.7)$ & 0.15 \\
\hline $\mathrm{IDL}-\mathrm{B}+\mathrm{C}$ & $22.0(18.7-29.2)$ & $20.6(17.5-27.0)$ & 0.21 \\
\hline $\mathrm{LDL}-1+2$ & $25.0(20.0-33.1)$ & $24.8(18.7-34.3)$ & 0.96 \\
\hline $\mathrm{LDL}-3+4+5+6+7$ & $1.8(0.0-4.5)$ & $2.0(0.0-6.0)$ & 0.75 \\
\hline
\end{tabular}

Values are medians (IQRs) of cholesterol from subfractions of intermediate-density lipoproteins (IDL) and low-density lipoproteins (LDL). IDL-A is considered nonatherogenic, while IDL-B and IDL-C are atherogenic. LDL-1 and LDL-2 are large and buoyant (nonatherogenic), while LDL-3 to LDL-7 are considered atherogenic. Lipoprotein subfractions were adjusted by total serum cholesterol and are expressed in $\mathrm{mg} / \mathrm{dL}$. Data were compared by the Mann-Whitney $\mathrm{U}$ test

efficiently decreased cholesterol content in the atherogenic subfractions (Delta, $P=0.043$, Mann-Whitney U test), whereas a similar effect was observed for the nonatherogenic LDL subfractions (Fig. 3).

Small, dense LDL (sdLDL) and large, buoyant LDL (lbLDL) particles were also examined by the Sampson equation (Table 4). No differences at baseline or after lipid-lowering treatments were found. However, lbLDL$C$ estimated by the Sampson equation was correlated with $\mathrm{LDL}_{1,2}$ (less atherogenic) obtained by the lipoprint system at baseline (rho $=0.43, P<0.001)$ and at 30 days (rho $=0.58, P<0.001$ ). In addition, sdLDL (Sampson equation) and $\mathrm{LDL}_{3-7}$ (lipoprint system) were also correlated at baseline (rho $=0.29, P=0.004)$ and at D30 (rho $=0.40, P<0.001)$.

\section{High-sensitivity C-reactive protein}

The levels of hsCRP at D1 (median [IQR]) were similar in both lipid-lowering treatment groups (25.6 [12.447.8] vs. 21.1 [10.2-46.9] $\mathrm{mg} / \mathrm{L}, P=0.45$, Mann-Whitney $U$ test) for the simvastatin plus ezetimibe and rosuvastatin groups, respectively. After 30 days, substantial and comparable decreases were found in both groups (2.14 [0.90-6.27] vs. $1.92[0.95-4.72] \mathrm{mg} / \mathrm{L}, P=0.78$, Mann-Whitney $U$ test) for the simvastatin plus ezetimibe and rosuvastatin groups, respectively. The delta of



B

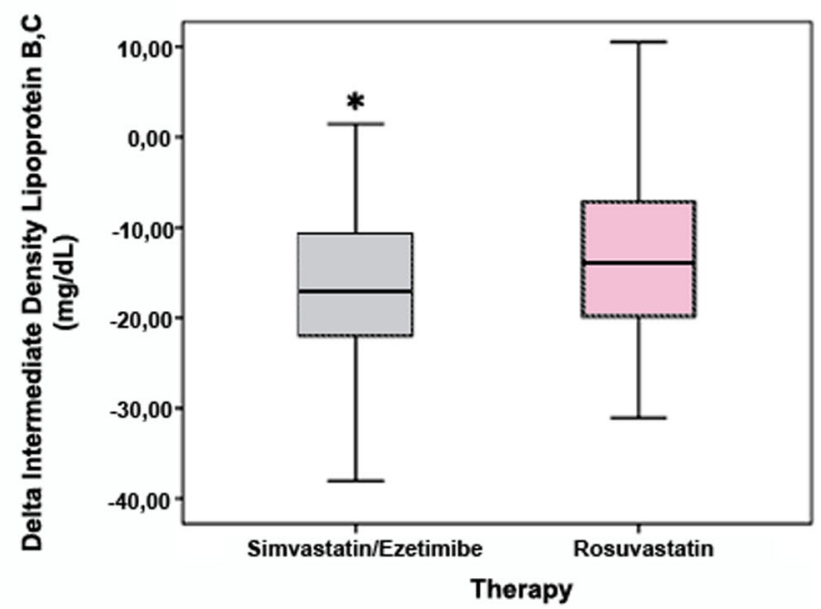

Fig. 2 Delta (final minus initial content in cholesterol) of intermediate-density lipoprotein (IDL) subfractions by lipid-lowering therapies. A The delta of IDL-A (nonatherogenic) was similar after simvastatin plus ezetimibe or rosuvastatin treatment. B The delta of IDL-B plus IDL-C (atherogenic) showed higher effectiveness with simvastin plus ezetimibe than rosuvastatin monotherapy (* $P=0.047$, Mann-Whitney $U$ test) 


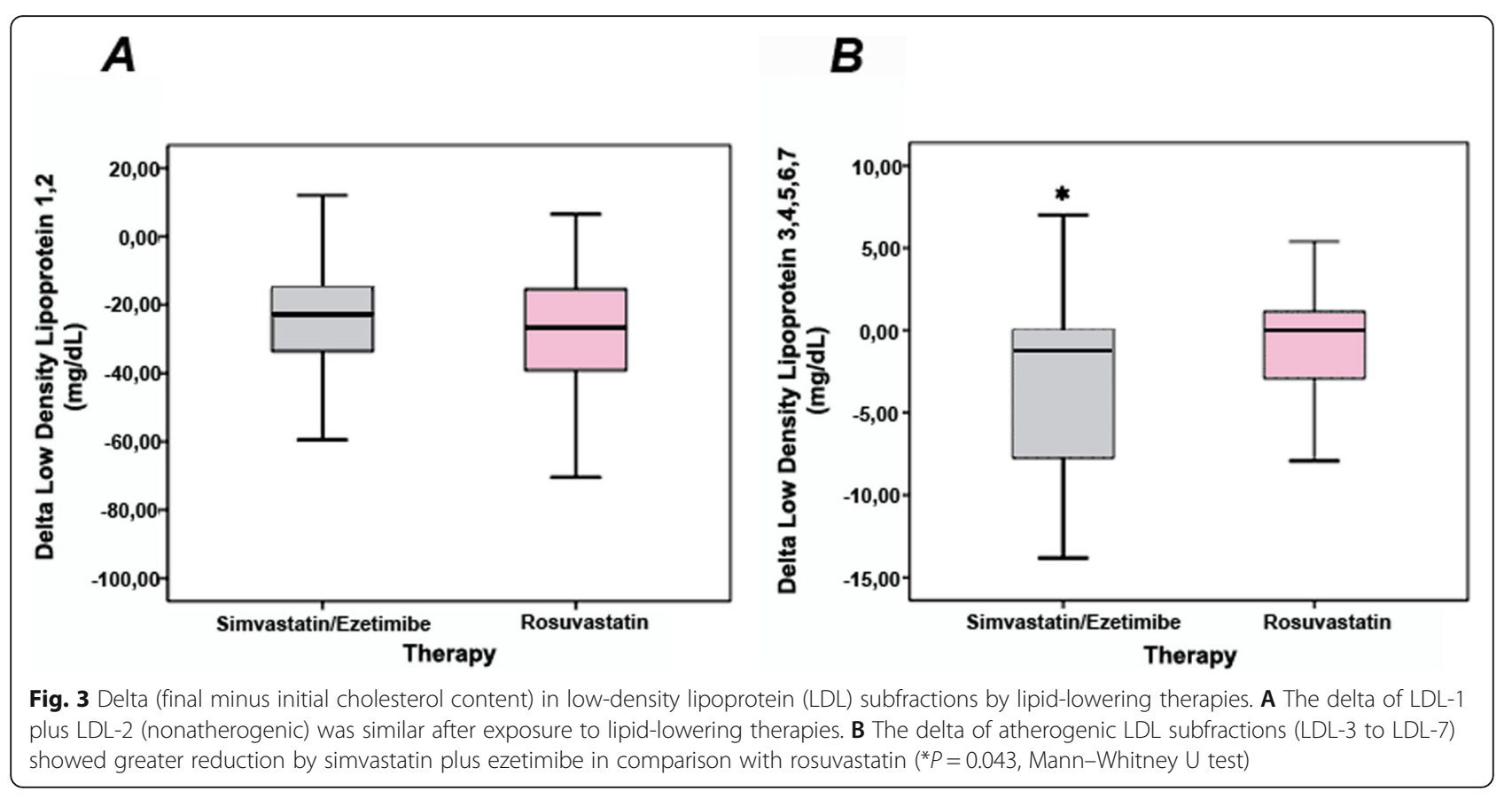

hsCRP titers (D30 - D1) observed after treatment was also similar between groups of lipid-lowering therapies $(P=0.91$, Mann-Whitney $U$ test). In addition, at D30, the achievement of hsCRP levels $<2 \mathrm{mg} / \mathrm{L}$ was similar between the lipid-lowering groups (44\% vs. $50 \%, P=$ 0.56, Pearson chi-square test) for the simvastatin plus ezetimibe and rosuvastatin groups. The achievement of both goals (LDL-C $<70 \mathrm{mg} / \mathrm{dL}$ and hsCRP levels $<2 \mathrm{mg}$ / L) was observed in 29 and $28 \%$ of patients treated with simvastatin plus ezetimibe and rosuvastatin, respectively $(P=0.97$, Pearson chi-square test).

\section{Discussion}

This study compared two highly effective lipid-lowering therapies in patients with STEMI and revealed that simvastatin plus ezetimibe more efficiently decreased the atherogenic subfractions of intermediate- and low-density lipoproteins than rosuvastatin monotherapy. Despite the strong evidence favouring statin monotherapy as a first option for lipid-lowering therapy in subjects at very high cardiovascular risk, the need for additional hypolipidaemic drugs is frequently necessary to achieve current LDL-C and non-HDL-C targets. In addition, simvastatin plus ezetimibe produced a similar reduction in hsCRP levels, a useful inflammatory biomarker with prognostic implications after acute myocardial infarction [26, 27]. However, approximately half of the patients in both arms of lipidlowering treatment remained with hsCRP levels above 2 $\mathrm{mg} / \mathrm{L}$, suggesting the need for additional therapy to reduce the inflammatory residual risk.

Table 4 Cholesterol content in subfractions of lipoproteins at baseline and after lipid-lowering therapy by the Sampson equation

\begin{tabular}{|c|c|c|c|}
\hline Lipoproteins & $\begin{array}{l}\text { Simvastatin plus ezetimibe } \\
N=50\end{array}$ & $\begin{array}{l}\text { Rosuvastatin monotherapy } \\
N=51\end{array}$ & $P$ value \\
\hline \multicolumn{4}{|c|}{ At baseline (D1) } \\
\hline LDL-C & $124(111-154)$ & $127(101-147)$ & 0.58 \\
\hline VLDL-C & $24(17-38)$ & $27(17-43)$ & 0.55 \\
\hline IbLDL-C & $88(69-110)$ & $84(62-99)$ & 0.32 \\
\hline sdLDL-C & $41(33-50)$ & $42(31-55)$ & 0.94 \\
\hline \multicolumn{4}{|c|}{ After 30 days (D30) } \\
\hline LDL-C & $54(39-76)$ & $58(46-80)$ & 0.23 \\
\hline VLDL-C & $19(15-27)$ & $21(15-28)$ & 0.58 \\
\hline IbLDL-C & $31(21-45)$ & $36(26-49)$ & 0.18 \\
\hline sdLDL-C & $23(17-30)$ & $23(20-30)$ & 0.36 \\
\hline
\end{tabular}

Values (mg/dL) are medians (IQRs) of cholesterol from subfractions of large and buoyant (IbLDL) or small and dense (sdLDL) lipoproteins obtained at baseline and after 30 days based on the Sampson equation from the standard lipid panel. Data were compared by the Mann-Whitney $U$ test 
Large observational studies have shown that small, dense LDL has been related to coronary heart disease [28-30]. The lower affinity of the small, dense LDL to LDL receptor results in a longer plasma resident time, increasing the opportunity for LDL oxidation and uptake by the vessel wall [6]. In the Justification for the Use of Statins in Prevention: an Intervention Trial Evaluating Rosuvastatin (JUPITER), rosuvastatin treatment was associated with smaller reductions in the small LDL subfractions than in the larger and buoyant subfractions [31]. Furthermore, incident cardiovascular disease was not associated with baseline LDL-C but with atherogenic non-HDL subfractions, suggesting a residual cholesterol risk [31]. In fact, by decreasing endogenous cholesterol synthesis, statins increase LDL receptor expression in the liver, promoting higher uptake of LDL particles, mainly those large and buoyant particles, which have higher affinity for the LDL receptor, explaining our findings (Fig. 3). Recently, lipid-lowering treatment with a monoclonal antibody against proprotein convertase subtilisin/kexin type 9 (PCSK9), which markedly increases the expression of the LDL receptor in the liver, resulted in a greater decrease in the large and buoyant LDL subfractions than in the smaller LDL subfractions [32]. Bays et al. examined the effects of atorvastatin $40 \mathrm{mg}$ when doubling the dose or combining it with ezetimibe among high-risk patients, and they found with both therapies that LDL particle pattern A (considered less atherogenic) was the lipoprotein predominantly cleared [33]. Together, these studies suggest the greatest effect in reducing large and buoyant LDL particles through the greatest affinity of these particles with LDL receptors, mainly following potent statins or PCSK9 inhibitors. Ezetimibe also increases the expression of LDL receptors, but possibly to a lesser magnitude [34] (Fig. 4).

The results obtained for the lipoprotein subfraction assessment using the Lipoprint system were correlated to the Sampson equation; however, using this last methodology, no significant differences between lipid-lowering therapies were found. Discrepancies between methods evaluating LDL subfractions have been previously reported [10]. In addition, important differences between the effects of highly effective lipid-lowering therapies on several lipids, examined by lipidomics, were recently reported, suggesting that small differences in the subfractions of LDL may be counterbalanced by favourable effects on other lipid classes, such as ceramides [35].

In our study, most atherogenic subfractions of intermediate-density lipoproteins (ILD B and IDL C) were also more effectively reduced by simvastatin plus ezetimibe therapy than with rosuvastatin monotherapy. These subfractions of intermediate-density lipoproteins can contribute to residual cholesterol risk, as shown in the JUPITER study [31]. Thus, decreasing non-HDL cholesterol by combined therapy not only increases the achievement of lipid targets but also seems to improve the pattern of lipoprotein subfractions. Thus, by similarly decreasing LDL and nonHDL cholesterol levels but with lower dependency of LDL receptors in the liver, the use of ezetimibe promoted a less atherogenic residual pattern of lipoproteins.

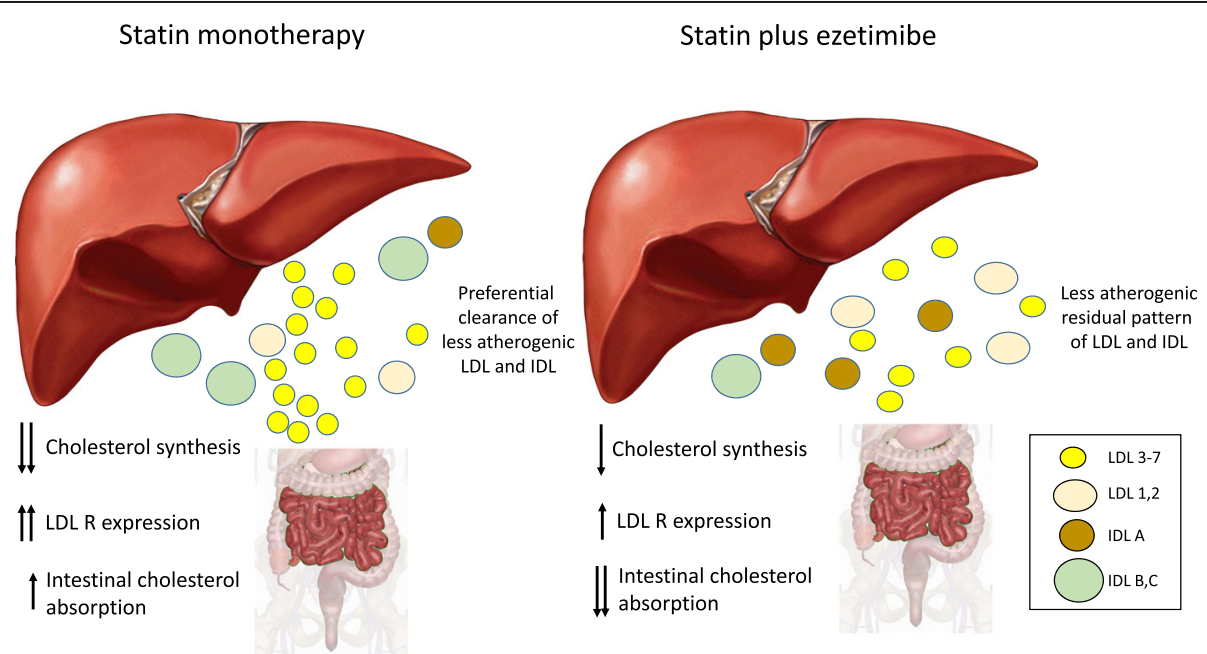

Fig. 4 Effects of lipid-lowering therapies on the atherogenic and nonatherogenic subfractions of lipoproteins. Rosuvastatin monotherapy decreased endogenous cholesterol synthesis and augmented both LDL receptor (LDL-R) expression and intestinal cholesterol absorption. The higher expression of LDL-R facilitated the clearance of large and buoyant LDL particles, which had more affinity to LDL-R than small dense particles. Following the use of simvastatin plus ezetimibe, other mechanisms were involved, and the decrease in cholesterol absorption by ezetimibe increased cholesterol synthesis and LDL-R expression. Differences in LDLR expression and lower intestinal cholesterol absorption may contribute to differences in the residual lipoprotein subfraction pattern. Higher effectiveness in the clearance of atherogenic IDL particles was also observed following simvastatin plus ezetimibe therapy compared with rosuvastatin monotherapy 
Recently, a machine learning-based clustering study among patients with STEMI under statin therapy evaluated a lipid panel composed of apo A1, Apo B, HDL-C, triglycerides, LDL-C, total cholesterol and lipoprotein (a) [Lp (a)]. The study revealed that the cluster with high levels of Lp (a) and low levels of apoA1 and HDL-C identified those patients with the highest recurrent events and mortality [36].

Even without a causal role in cardiovascular disease, hsCRP levels have been related to long-term prognosis after myocardial infarction [37], and the achievement of dual goals (LDL-C and hsCRP) has identified patients with better event-free survival in the Pravastatin or Atorvastatin Evaluation and Infection Therapy trial (PROVEIT) [38] and the Improved Reduction of Outcomes: Vytorin Efficacy International Trial (IMPROVE-IT) [21] trials. In our study, the achievement of both targets (LDL-C $<70 \mathrm{mg} / \mathrm{dL}$ and $\mathrm{hsCRP}<2 \mathrm{mg} / \mathrm{L}$ ) was reported in a similar proportion of patients treated with simvastatin plus ezetimibe or rosuvastatin. However, the achievement of these goals was observed by less than approximately one-third of these patients. Thus, the need for additional lipid-lowering and anti-inflammatory therapy seems necessary to reduce the inflammatory residual risk, as has been more recently demonstrated [38-43]. Finally, combined therapy to achieve cholesterol goals using multiple mechanisms appears to be safer in the long term of intensive lipid-lowering therapy, allowing exposure to lower statin doses and reducing pharmacokinetic interactions and adverse muscle events [44].

\section{Comparisons with other studies and what the current work adds to the existing knowledge}

This study compared a potent statin with a moderately potent statin combined with ezetimibe in lipoprotein subclasses and revealed differences in lipoprotein subfractions between these lipid-lowering strategies. This head-to-head randomized comparison adds new information to previous studies reporting the effects of potent statins alone [31] or combined with ezetimibe [33].

\section{Strengths and limitations}

This study shows a direct comparison between two lipid-lowering therapies aimed at achieving $50 \%$ or more LDL-C reduction and reveals important aspects. First, there were some differences between treatments in the LDL subfractions, despite similar standard lipid panels. Second, some goals were not achieved despite the use of recommended lipid-lowering therapies, particularly among very high-risk patients $[1,2]$. The number of patients was relatively small but included only patients with STEMI under a pharmacoinvasive strategy, with comparable baseline clinical and laboratory characteristics, including troponin levels. Despite small differences between lipid-lowering therapies, these findings are important due to the direct comparisons between these lipid-lowering therapies after myocardial infarction, a period of high rates of atherosclerotic recurrent events.

\section{Conclusion}

Lipid-lowering therapy with simvastatin plus ezetimibe was associated with better effects on the atherogenic LDL and IDL subfractions than rosuvastatin monotherapy. These differences were noted despite similar effects in the classic lipid profile and may contribute to residual cardiovascular risk.

\section{What are the clinical relevance and future perspectives?} The findings of the study suggest that a better pattern of LDL subfractions can be obtained by the combination of ezetimibe with a statin of moderate potency in comparison to a more potent statin. This result shows that statins combined with ezetimibe seem important not only for achieving lipid targets but also for better LDL subfraction patterns.

\section{Abbreviations \\ LDL: Low-density lipoprotein; IDL: Intermediate-density lipoprotein; hSCRP: high-sensitivity C-reactive protein; STEMI: ST-segment elevation acute myocardial infarction; PCl: Percutaneous coronary intervention; IbLDL: Large buoyant LDL; sdLDL: Small dense LDL; hsTNT: high-sensitivity troponin T; PCSK9: Proprotein convertase subtilisin/kexin type 9; Lp (a): Lipoprotein (a)}

\section{Acknowledgements}

The authors would like to thank the physicians and nurses from the emergency department of Hospital Sao Paulo for the initial screening and care of patients.

\section{Authors' contributions}

LCSP conducted experiments and data treatments and prepared and revised the manuscript. APQM performed experiments and analysed data. MCOI designed the study and revised the manuscript. NRTD performed and analysed lipoprotein subfraction data. AMFN participated in the study design, contributed financial support, and revised the manuscript. CNF revised the manuscript and helped with figures and data treatment. AC conducted and analysed coronary angiography and revised the manuscript. HTB contributed clinical data treatment and assistance. RMSP participated in the study design and revised the manuscript. FTM collected clinical data and provided medical assistance. ASFB helped with clinical data and medical assistance. FAHF designed the study, prepared and revised the manuscript and acquired funding for it. The author(s) read and approved the final manuscript.

\section{Funding \\ This study was supported by the Research Foundation of the State of Sao Paulo - FAPESP (grant \# 2012/51692-7), by the Brazilian National Council for Scientific and Technological Development - CNPq (grant \# 428793/2016-9), by the National Institute of Science and Technology of Complex Fluids - INCT-FCX (grant \# 2014/50983-3), and through an investigator-initiated grant from AstraZeneca (ESR 14-10726). The study design, data collection, statis- tical analysis, or publications were not influenced by the sponsors and are the exclusive responsibility of the investigators.}

Availability of data and materials

The analysed database is available from the corresponding author upon request. 


\section{Declarations}

\section{Ethics approval and consent to participate}

The study protocol was approved by the local ethics committee (Escola Paulista de Medicina - UNIFESP IRB 0297/2014; CAAE: 71652417.3.0000.5505), which follows the latest Declaration of Helsinki, and written informed consent was provided by all patients before their inclusion.

\section{Consent for publication}

All authors consented to publish the results shown.

\section{Competing interests}

Dr. FAH Fonseca declares receiving consulting fees from NovoNordisk, Novartis, and AstraZeneca, lecture fees from Novo Nordisk, Abbott, Ache, Biolab, Libbs, Ely Lilly, Sanofi Aventis, Amgen, and AstraZeneca, and travel support from Amgen, Bayer and NovoNordisk. MC Izar declares receiving consulting fees from Amgen, PTC, Amryt Pharma, Novartis, lecture fees from Amgen, PTC, Libbs, Ache, and travel support from Novo Nordisk and Amgen. The authors have no additional relevant financial or nonfinancial interests to disclose.

\section{Author details}

'Escola Paulista de Medicina, Setor de Lípides, Aterosclerose e Biologia Vascular, Universidade Federal de São Paulo, UNIFESP, Rua Loefgren 1350 São Paulo, SP 04040-001, Brazil. Faculdade de Saúde Pública, Universidade de São Paulo, USP, São Paulo, Brazil. ${ }^{3}$ Instituto de Física, Universidade de São Paulo, USP, São Paulo, Brazil. ${ }^{4}$ Universidade Santo Amaro, UNISA, São Paulo, Brazil.

Received: 3 August 2021 Accepted: 13 September 2021

Published online: 29 September 2021

\section{References}

1. Mach F, Baigent C, Catapano AL, Koskinas KC, Casula M, Badimon L, et al. 2019 ESC/EAS quidelines for the management of dyslipidaemias: lipid modification to reduce cardiovascular risk. Eur Heart J. 2020;41(1):111-88. https://doi.org/10.1093/eurheartj/ehz455.

2. Grundy SM, Stone NJ, Bailey AL, Beam C, Birtcher KK, Blumenthal RS, et al. 2018 AHA/ACC/AACVPR/AAPA/ABC/ACPM/ADA/AGS/APhA/ASPC/NLA PCNA guideline on the Management of Blood Cholesterol: a report of the American College of Cardiology/American Heart Association task force on clinical practice guidelines. Circulation. 2019;139(25):e1046-81. https://doi. org/10.1161/CIR.0000000000000624

3. Kini AS, Baber U, Kovacic JC, Limaye A, Ali ZA, Sweeny J, et al. Changes in plaque lipid content after short-term intensive versus standard statin therapy: the YELLOW trial (reduction in yellow plaque by aggressive lipidlowering therapy). J Am Coll Cardiol. 2013;62(1):21-9. https://doi.org/10.101 6/j.jacc.2013.03.058.

4. Yano H, Horinaka S, Ishimitsu T. Effect of evolocumab therapy on coronary fibrous cap thickness assessed by optical coherence tomography in patients with acute coronary syndrome. J Cardiol. 2020;75(3):289-95. https://doi. org/10.1016/j.jjcc.2019.08.002.

5. Puri R, Nissen SE, Shao M, Ballantyne CM, Barter PJ, Chapman MJ, et al. Coronary atheroma volume and cardiovascular events during maximally intensive statin therapy. Eur Heart J. 2013;34(41):3182-90. https://doi.org/1 0.1093/eurheartj/eht260.

6. Langlois MR, Chapman MJ, Cobbaert C, Mora S, Remaley AT, Ros E, et al. Quantifying Atherogenic lipoproteins: current and future challenges in the era of personalized medicine and very low concentrations of LDL cholesterol. A consensus Statement from EAS and EFLM. Clin Chem. 2018; 64(7):1006-33. https://doi.org/10.1373/clinchem.2018.287037.

7. Higashioka M, Sakata S, Honda T, Hata J, Yoshida D, Hirakawa Y, et al. Small dense low-density lipoprotein cholesterol and the risk of coronary heart disease in a Japanese community. J Atheroscler Thromb. 2020;27(7):669-82. https://doi.org/10.5551/jat.51961.

8. Liou L, Kaptoge S. Association of small, dense LDL-cholesterol concentration and lipoprotein particle characteristics with coronary heart disease: A systematic review and meta-analysis. PLoS One. 2020;15(11):e0241993.

9. Duan R, Xue W, Wang K, et al. Estimation of the LDL subclasses in ischemic stroke as a risk factor in a Chinese population. BioMed Central Neurol. 2020; 20(1):414.
10. Kanonidou C. Small dense low-density lipoprotein: analytical review. Clin Chim Acta. 2021;520:172-8. https://doi.org/10.1016/..cca.2021.06.012.

11. Sampson M, Wolska A, Warnick R, Lucero D, Remaley AT. A new equation based on the standard lipid panel for calculating small dense low-density lipoprotein-cholesterol and its use as a risk-enhancer test. Clin Chem. 2021; 67(7):987-97. https://doi.org/10.1093/clinchem/hvab048.

12. Yu M, Liang C, Kong Q, Wang Y, Li M. Efficacy of combination therapy with ezetimibe and statins versus a double dose of statin monotherapy in participants with hypercholesterolemia: a meta-analysis of literature. Lipids Health Dis. 2020;19(1):1.

13. Othman RA, Myrie SB, Mymin D, Roullet JB, Steiner RD, Jones PJH. Effect of ezetimibe on low- and high-density lipoprotein subclasses in sitosterolemia. Atherosclerosis. 2017;260:27-33. https://doi.org/10.1016/j.atherosclerosis.201 7.03.015.

14. Tribble DL, Farnier M, Macdonell G, Perevozskaya I, Davies MJ, Gumbiner B, et al. Effects of fenofibrate and ezetimibe, both as monotherapy and in coadministration, on cholesterol mass within lipoprotein subfractions and low-density lipoprotein peak particle size in patients with mixed hyperlipidemia. Metabolism. 2008;57(6):796-801. https://doi.org/10.1016/j. metabol.2008.01.026

15. Winkler K, Jacob S, Müller-Schewe T, Hoffmann MM, Konrad T. Ezetimibe alone and in combination lowers the concentration of small, dense lowdensity lipoproteins in type 2 diabetes mellitus. Atherosclerosis. 2012;220(1): 189-93.

16. Ose L, Reyes R, Johnson-Levonas AO, Sapre A, Tribble DL, Musliner T. Effects of ezetimibe/simvastatin on lipoprotein subfractions in patients with primary hypercholesterolemia: an exploratory analysis of archived samples using two commercially available techniques. Clin Ther. 2007;29(11):241932. https://doi.org/10.1016/j.clinthera.2007.10.004.

17. Katsiki N, Athyros VG, Karagiannis A, Mikhailidis DP. Ezetimibe and low density lipoprotein subfractions: an ongoing debate. Curr Med Res Opin. 2011;27(3):693-5.

18. Berneis K, Rizzo M, Berthold HK, Spinas GA, Krone W, Gouni-Berthold I. Ezetimibe alone or in combination with simvastatin increases small dense low-density lipoproteins in healthy men: a randomized trial. Eur Heart J. 2010;31(13):1633-9. https://doi.org/10.1093/eurhearti/ehq181.

19. Thongtang N, Diffenderfer MR, Ooi EMM, Barrett PHR, Turner SM, le NA, et al. Metabolism and proteomics of large and small dense LDL in combined hyperlipidemia: effects of rosuvastatin. J Lipid Res. 2017;58(7): 1315-24. https://doi.org/10.1194/jr.M073882.

20. Ridker PM, Danielson E, Fonseca FA, Genest J, Gotto AM Jr, Kastelein JJP, et al. Reduction in C-reactive protein and LDL cholesterol and cardiovascular event rates after initiation of rosuvastatin: a prospective study of the JUPITER trial. Lancet. 2009;373(9670):1175-82. https://doi.org/10.1016/ S0140-6736(09)60447-5.

21. Bohula EA, Giugliano RP, Cannon CP, Zhou J, Murphy SA, White JA, et al. Achievement of dual low-density lipoprotein cholesterol and highsensitivity C-reactive protein targets more frequent with the addition of ezetimibe to simvastatin and associated with better outcomes in IMPROVEIT. Circulation. 2015;132(13):1224-33. https://doi.org/10.1161/CIRCULATIONA HA. 115.018381.

22. Bhagavathula AS, Aldhaleei WA, Al Matrooshi NO, Rahmani J. Efficacy of statin/Ezetimibe for secondary prevention of atherosclerotic cardiovascular disease in Asian populations: a systematic review and Meta-analysis of randomized controlled trials. Clin Drug Investig. 2020;40(9):809-26. https:// doi.org/10.1007/s40261-020-00951-1.

23. Fonseca FAH, Izar MC, Maugeri IML, et al. Effects of four antiplatelet/statin combined strategies on immune and inflammatory responses in patients with acute myocardial infarction undergoing pharmacoinvasive strategy: Design and rationale of the B and T Types of Lymphocytes Evaluation in Acute Myocardial Infarction (BATTLE-AMI) study: study protocol for a randomized controlled trial. Trials. 2017:18(1):601.

24. Hoefner DM, Hodel SD, O'Brien JF, Branum EL, Sun D, Meissner I, et al. Development of a rapid, quantitative method for $L D L$ subfractionation with use of the Quantimetrix Lipoprint LDL system. Clin Chem. 2001;47(2):26674. https://doi.org/10.1093/clinchem/47.2.266.

25. Varady KA, Lamarche B. Lipoprint adequately estimates LDL size distribution, but not absolute size, versus polyacrylamide gradient gel electrophoresis. Lipids. 2011;46(12):1163-7. https://doi.org/10.1007/s11745-011-3611-8.

26. Ridker PM, Everett BM, Thuren T, MacFadyen JG, Chang WH, Ballantyne C, et al. Antiinflammatory therapy with Canakinumab for atherosclerotic 
disease. N Engl J Med. 2017;377(12):1119-31. https://doi.org/10.1056/ NEJMoa1707914.

27. Carrero JJ, Franko MA, Obergfell A, Gabrielsen A, Jernberg T. hsCRP Level and the Risk of Death or Recurrent Cardiovascular Events in Patients With Myocardial Infarction: a Healthcare-Based Study. J Am Heart Assoc. 2019; 8(11):e012638.

28. Ai M, Otokozawa S, Asztalos BF, Ito Y, Nakajima K, White CC, et al. Small dense LDL cholesterol and coronary heart disease: results from the Framingham offspring study. Clin Chem. 2010;56(6):967-76. https://doi.org/1 0.1373/clinchem.2009.137489.

29. Tsai MY, Steffen BT, Guan W, McClelland RL, Warnick R, McConnell J, et al. New automated assay of small dense low-density lipoprotein cholesterol identifies risk of coronary heart disease: the multi-ethnic study of atherosclerosis. Arterioscler Thromb Vasc Biol. 2014;34(1):196-201. https://doi.org/10.1161/ATVBAHA.113.302401

30. Hoogeveen RC, Gaubatz JW, Sun W, Dodge RC, Crosby JR, Jiang J, et al. Small dense low-density lipoprotein-cholesterol concentrations predict risk for coronary heart disease: the atherosclerosis risk in communities (ARIC) study. Arterioscler Thromb Vasc Biol. 2014;34(5):1069-77. https://doi.org/1 0.1161/ATVBAHA.114.303284

31. Mora S, Caulfield MP, Wohlgemuth J, Chen Z, Superko HR, Rowland CM, et al. Atherogenic lipoprotein subfractions determined by ion mobility and first cardiovascular events after random allocation to high-intensity statin or placebo: the justification for the use of statins in prevention: an intervention trial evaluating Rosuvastatin (JUPITER) trial. Circulation. 2015;132(23):2220-9. https://doi.org/10.1161/CIRCULATIONAHA.115.016857.

32. Baruch A, Mosesova S, Davis JD, Budha N, Vilimovskij A, Kahn R, et al. Effects of RG7652, a monoclonal antibody against PCSK9, on LDL-C, LDL-C subfractions, and inflammatory biomarkers in patients at high risk of or with established coronary heart disease (from the phase 2 EQUATOR study). Am J Cardiol. 2017;119(10):1576-83. https://doi.org/1 0.1016/j.amjcard.2017.02.020.

33. Bays $\mathrm{H}$, Conard S, Leiter LA, Bird S, Jensen E, Hanson ME, et al. Are posttreatment low-density lipoprotein subclass pattern analyses potentially misleading? Lipids Health Dis. 2010;9(1):136. https://doi.org/10.1186/1476511X-9-136.

34. Xu RX, Liu J, Li XL, Li S, Zhang Y, Jia YJ, et al. Impacts of ezetimibe on PCSK9 in rats: study on the expression in different organs and the potential mechanisms. J Transl Med. 2015;13(1):87. https://doi.org/10.1186/s12967-01 5-0452-x.

35. Klassen A, Faccio AT, Picossi CRC, et al. Evaluation of two highly effective lipid-lowering therapies in subjects with acute myocardial infarction. Sci Rep. 2021;11(1):15973.

36. Xue Y, Shen J, Hong W, et al. Risk stratification of ST-segment elevation myocardial infarction (STEMI) patients using machine learning based on lipid profiles. Lipids Health Dis. 2021;20(1):48.

37. Pokharel Y, Sharma PP, Qintar M, Lu Y, Tang Y, Jones P, et al. High-sensitivity C-reactive protein levels and health status outcomes after myocardial infarction. Atherosclerosis. 2017;266:16-23. https://doi.org/10.1016/j.a therosclerosis.2017.09.019.

38. Ridker PM, Morrow DA, Rose LM, Rifai N, Cannon CP, Braunwald E. Relative efficacy of atorvastatin $80 \mathrm{mg}$ and pravastatin $40 \mathrm{mg}$ in achieving the dual goals of low-density lipoprotein cholesterol $<70 \mathrm{mg} / \mathrm{dl}$ and C-reactive protein <2 mg/l: an analysis of the PROVE-IT TIMI-22 trial. J Am Coll Cardiol. 2005:45(10):1644-8. https://doi.org/10.1016/.j.jacc.2005.02.080.

39. Ridker PM, Libby P, MacFadyen JG, Thuren T, Ballantyne C, Fonseca F, et al. Modulation of the interleukin-6 signalling pathway and incidence rates of atherosclerotic events and all-cause mortality: analyses from the Canakinumab anti-inflammatory thrombosis outcomes study (CANTOS). Eur Heart J. 2018:39(38):3499-507. https://doi.org/10.1093/eurheartj/ehy310.

40. Tardif JC, Kouz S, Waters DD, Bertrand OF, Diaz R, Maggioni AP, et al. Efficacy and safety of low-dose colchicine after myocardial infarction. N Engl J Med. 2019;381(26):2497-505. https://doi.org/10.1056/NEJMoa1912388.

41. Bouabdallaoui N, Tardif JC, Waters DD, Pinto FJ, Maggioni AP, Diaz R, et al. Time-to-treatment initiation of colchicine and cardiovascular outcomes after myocardial infarction in the colchicine cardiovascular outcomes trial (COLCOT). Eur Heart J. 2020;41(42):4092-9. https://doi.org/10.1093/eurheartj/ ehaa659.

42. Schwartz GG, Steg PG, Szarek M, Bhatt DL, Bittner VA, Diaz R, et al. Alirocumab and cardiovascular outcomes after acute coronary syndrome. N Engl J Med. 2018;379(22):2097-107. https://doi.org/10.1056/NEJMoa1801174.
43. Bohula EA, Giugliano RP, Leiter LA, Verma S, Park JG, Sever PS, et al. Inflammatory and cholesterol risk in the FOURIER trial. Circulation. 2018; 138(2):131-40. https://doi.org/10.1161/CIRCULATIONAHA.118.034032.

44. Sposito AC, Faria Neto JR, Carvalho LS, Lorenzatti A, Cafferata A, Elikir G, et al. Statin-associated muscle symptoms: position paper from the LusoLatin American consortium. Curr Med Res Opin. 2017;33(2):239-51. https://doi.org/10.1080/03007995.2016.1252740.

\section{Publisher's Note}

Springer Nature remains neutral with regard to jurisdictional claims in published maps and institutional affiliations.
Ready to submit your research? Choose BMC and benefit from:

- fast, convenient online submission

- thorough peer review by experienced researchers in your field

- rapid publication on acceptance

- support for research data, including large and complex data types

- gold Open Access which fosters wider collaboration and increased citations

- maximum visibility for your research: over $100 \mathrm{M}$ website views per year

At BMC, research is always in progress.

Learn more biomedcentral.com/submissions 